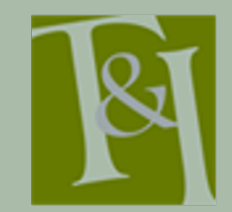

The International Journal for Translation \& Interpreting Research trans-int.org

\section{Style shift in translation: The case of translating Susan Glaspell's Trifles into Arabic}

\author{
Abbas Brashi \\ Umm Al-Qura University, Saudi Arabia \\ asbrashi@uqu.edu.sa
}

DOI: 10.12807/ti.113202.2021.a05

\begin{abstract}
This study examines style shifting in an Arabic translation of Susan Glaspell's play, Trifles by Abbas Brashi. It presents an overview of the play, as well as its importance and relevance to Arab culture. It describes the different varieties of Arabic that exist as well as the one chosen for the translation, namely Modern Standard Arabic. The paper explains that the formal style of the target language text was chosen for the sake of wide readability and comprehensibility, as dialectal varieties of Arabic differ across and within Arab states and there is no standardised script. The other reason for the shift is to adhere to the norms of acceptable Arabic writing. The style shift observed in the translation of Trifles into Arabic is demonstrated in the translation of a number of linguistic phenomena, namely contraction, elision, subject-verb agreement, and figurative multi-word expressions. The paper concludes that the formal Arabic version of Trifles may later be shifted to different informal dialectal varieties of Arabic when it is to be performed on stage. Therefore, the formal Arabic version of the play may be customised or adapted to one or more specific dialects of Arabic according to the time and place of each performance.
\end{abstract}

Keywords: Susan Glaspell; Trifles; drama; literary translation; Arabic translation; style shift.

\section{Introduction}

Susan Keating Glaspell (1876-1948) was an American dramatist and novelist. She was one of the first feminists in theatre, who stated her opposition to the boundaries and restrictions placed on women in the workplace. Glaspell wrote more than forty short stories, twenty plays, and ten novels. Among Glaspell's primary literary works is her one-act play, Trifles (1916). In 1917, Glaspell turned the play into a short story entitled "A Jury of her peers".

Susan Glaspell based the short play, Trifles, on the murder of a sixty-yearold farmer, John Hossack. Glaspell covered the murder case during her work as a journalist with the Des Moines Daily News after she graduated from Drake University before pursuing her writing career. She travelled to the scene of the crime in Indianola, Iowa, where the farmer, John Hossack, had been murdered after midnight on the $2^{\text {nd }}$ of December, 1900. His wife, Margaret Hossack, was accused of murdering her husband with an axe while he was sleeping in bed. The incident took place at a time where women had very little protection from domestic abuse and had not yet been given the right to vote. In most US states, women could not sit on juries and it was not until 1920 that the $19^{\text {th }}$ Amendment granted women the suffrage.

This study examines style shifting in Abbas Brashi's 2019 Arabic translation of Susan Glaspell's 1916 play Trifles. It presents an overview of the play and its importance and relevance to Arab culture. The paper then discusses 
the different varieties of the Arabic language and the one used in translating the play, followed by a justification of the choice. The style shift observed in the translation of Trifles into Arabic is demonstrated in the translation of a number of linguistic phenomena, namely contraction, elision, subject-verb agreement, and figurative multi-word expressions.

\section{An overview of Trifles}

Susan Glaspell's one-act play Trifles concerns the killing of an oppressive husband by his emotionally abused wife. Glaspell wrote Trifles in an attempt to re-address the John Hossack murder case from the point of view of women who might not share the socially dominant viewpoint on the nature of marital disagreement and domestic unhappiness (Hilton, 2011). For example, in the play, the historical figure Margaret Hossack becomes the character Minnie Foster Wright. One can notice the allusion in the name Minnie, suggesting someone small or insignificant. Furthermore, one can notice the pun on the surname to bring attention to her lack of rights or her right to react against her abusive husband (Jabboury, 2007). In Trifles, Glaspell gives the wife, Mrs Wright, a motive for the murder from a feminist perspective. Therefore, the play is a fictional retelling of the case which 'solves' the murder in a way that highlights a social ill that was little discussed at the time.

Trifles takes place in one location, the house of Mr John Wright and his wife Mrs Minnie Wright, two off-stage characters. The play starts with two women and three men going into the desolate rural house of the Wrights where there are "incomplete" things all over the place. There are unwashed pans under the sink, a loaf of bread outside the breadbox, a dishtowel on the table and other signs of unfinished work. The audience of the play can clearly see that the residents might have departed the house in a rush or were forced to depart in unpredictable circumstances.

The characters of the play include the sheriff, Mr Henry Peters; Mrs Peters, the sheriff's wife; Mr Lewis Hale, a farmer and neighbour of the Wrights; Mrs Hale, wife of Mr Hale; and the county attorney, Mr George Henderson. We are also introduced to five characters who never set foot on the stage - namely the victim, Mr John Wright; Mrs Minnie Wright, the victim's wife; Frank, the deputy sheriff; Harry, a helper of Mr Lewis Hale; and Dr Lloyd, the coroner.

The characters are at the Wright's house to inspect the crime scene and investigate the murder of Mr John Wright. By this time, Mrs Minnie Wright has already been taken to jail and almost everyone considers her guilty of the murder. Mrs Hale and Mrs Peters are there with their husbands to collect a couple of things that Minnie may need while she is in prison. The sheriff and the county attorney are present to investigate the murder and find out who committed it. Mr Hale was the first to know about the incident. He went to $\mathrm{Mr}$ Wright's house to speak with him in the morning of the previous day when he saw Mrs Wright on a rocking chair and asked after her husband. She said that somebody had strangled him to death with a rope while he was asleep. He then reported the murder to the sheriff's office. Mrs Wright claimed that she did not hear a thing while her husband was being murdered as she is a heavy sleeper. The sheriff and the county attorney could not believe that Mrs Wright had not heard any sound or felt any movement while her husband was being murdered.

Susan Glaspell's Trifles addresses the story of Mrs Minnie Wright, a seemingly calm wife who loses control of her emotions and murders her abusive and aggressive husband who killed her canary bird. Her motive for murder goes far beyond the killing of the bird, as the canary was a symbol of freedom for her. In Trifles, the protagonist, Mrs Wright, experiences an array of emotions, such as anger, shock, numbness, denial, and profound sadness, especially 
because the death of her bird was unexpected (Sutton, 2008). She considers the loss of her bird as an amputation, as if she had lost something vital.

The title of the play was chosen from a line delivered by Mr Hale: "Well, women are used to worrying about trifles" (line 132). The title is ironic in that Mrs Minnie Wright appears to be more worried about trifles than she is about being arrested for murder.

Kennedy (2014) notes that Trifles is a unique play for two reasons. First, the main character, Mrs Wright, is never present on stage. Secondly, the wives (Mrs Hale and Mrs Peters) of the two male investigators, who are dismissed and ignored during the investigation process, identify signs and clues of abuse within Mrs Wright's home and then deduce why she might have killed her husband. At the end of the play, Mrs Hale and Mrs Peters choose to keep these clues to themselves in solidarity with Mrs Wright's precarious situation and thus the motive for the murder remains vague (Holstein, 2003).

\section{Translating Trifles into Arabic}

Trifles is one of the most commonly taught plays in American literature classes and is frequently anthologised in American literature textbooks. Furthermore, it is one of the earliest examples of American feminist drama and is still considered to be one of the most eminent one-act plays in the American canon (Kennedy, 2014).

The play explores a topic that is evident in almost all cultures, including that of the Arab world. It is concerned with the social issue of women who face depression when they are ignored, abandoned or possibly disparaged by their husbands. The sense of being lost is more profound when one needs help but cannot obtain it. There is a sense of ambiguity regarding the emotions the women feel and their uncertainty in how to express themselves. Accordingly, reading literary works of a culture different from one's own may assist in developing a wider knowledge of the world, which in turn can have numerous effects on a person. In other words, translated literature enables people to understand and appreciate the world around them. To that end, the culture of one community may positively or negatively influence the behaviour, beliefs, attitudes and values of another community through translation.

Drama has always offered a rich context for obtaining information and expanding our understanding of our own cultures and those of others through translation. Aaltonen (2010) affirms that plays open up windows to societies and cultures. A play may assist its readers and viewers in recognising and appreciating sophisticated cultural aspects of a particular society. These aspects are usually associated with specific situations within a cultural context. Needless to say, translated plays share the same associations. Similarly, Albakry (2014) states that translated foreign drama may provide a chance for audiences to gain a close understanding of a different culture and a specific time situated in the past. Therefore, audiences who appreciate literary works, including Arab readers and viewers, would most likely enjoy drama that addresses social issues and problems that are evident in their own societies. Jayyusi (2006), for example, confirms that Arab nations have shown great interest in drama at both institutional and community levels as it is a significant tool for cultural progress and the attainment of a high literary level. She notes that among the most successful social topics that are addressed in theatre are marital problems (Jayyusi, 2006). Therefore, publishing companies, copyright holders, and thus translators may well believe that it is a social responsibility to translate literary works and reveal their social and cultural aspects to audiences who may otherwise not have access to it due to the language barriers. 


\section{The form of Arabic used in the translation of Trifles}

Generally speaking, the Arabic language may be classified into three categories: Classical Arabic (highly formal), Modern Standard Arabic (formal), and colloquial or dialectal varieties (informal). To most speakers of Arabic, Classical Arabic is considered the language of the old revealed religious scriptures. On the one hand, Modern Standard Arabic is the modern descendant of Classical Arabic that retains the essentials of its syntactic structures. However, it has undergone several changes, and is probably continuing to change in terms of words and phrases (Holes, 2004). Modern Standard Arabic is considered to be a unified version of Arabic that is used all over the Arab world and has developed to become the basic norm in the language (Al Merabi, 2011). It is the standard medium for formal discourse, and so it is used in all forms of writing, including most literary works. In addition, Modern Standard Arabic is the language used in news channels, governmental speeches, official statements and announcements, and most significantly in all educational institutions (Holes, 2004).

On the other hand, informal Arabic refers to a broad range of dialectal variations of spoken language depending on the area, region or country where it is spoken. It is used for casual or informal communication and can sometimes not be easily understood by native speakers in other Arab countries or regions. Furthermore, dialectal Arabic use is generally limited to casual writing (e.g. in social media platforms). However, educated users of Arabic tend to write using a language style that is closer to formal Modern Standard Arabic, even in informal settings.

Arabic linguists generally attempt to resist dialectal Arabic in writing and thus try to regulate the written language (Al Merabi, 2011). Their purpose is normally to maintain the purity of the Arabic language and protect it from dialectal variations and foreign language influences. To a great extent, the media in all Arab countries have contributed to the promotion of Modern Standard Arabic. In my view, the main reason for encouraging and supporting the standard form of the language is that many dialectal variations of Arabic are dissimilar enough in pronunciation and vocabulary to sometimes result in miscommunication.

For the sake of wide readability and comprehensibility, Trifles has been translated into Modern Standard Arabic because of its ubiquity across the Arab world. In contrast, dialectal varieties of Arabic differ across and within Arab states and do not have a standardised script (Albirini, 2014). This is probably the reason why dialectal Arabic is often referred to as spoken Arabic. In addition, these dialectal varieties are not consistent as informal Arabic tends to change significantly over time.

Needless to say, this is not the only case where informal language has been translated into formal Arabic. In 2006, Kamel Youssef translated Henrik Ibsen's famous play $A$ Doll's House (1879) into formal Arabic, which was also performed in formal Arabic. In my opinion, translating Trifles into Modern Standard Arabic provides an opportunity for the Arabic version of the play to later be adapted or customised to different varieties of dialectal Arabic depending on where it will be performed.

\section{Style shift in translation}

Style, according to Leech and Short, is "the way in which language is used in a given context, by a given person, for a given purpose" (2007, p.10). They emphasise that style is a result of purposeful choices made by speakers and writers. With regard to translation, there are two categories of style: the source text style and the target text style. Huang and Chu (2014) stress that the source 
text style results from conscious choices and subconscious or habitual use of the source language by the speaker or writer and is usually referred to as the author's style. However, the target text style may be influenced by the source text style itself, the translator's preferences corresponding to the source text and their subconscious use of the target language, and, most importantly, the target language norms. Accordingly, research in the area of style in translation is concerned with the way the source text style is rendered into the target language.

Variations in language style develop from the fact that different language users have the choice to express themselves in different modes. A language user could possibly express the same concept somewhat differently depending on the specific situation and audience. Formal language, for instance, is normally used in official and serious situations, such as books, reports, journal articles, news reports, and official speeches and documents. Conversely, informal language is generally used in routine daily conversations and other forms of communication in casual settings, such as personal communication and social media interactions.

Informal style elements in a text are cultural aspects that may cause difficulty in translation. The translator would first be concerned with understanding the meaning of the text and then with how to render the meaning into the target language. Therefore, it is a matter of comprehensibility for both the translator and subsequently the target language audience.

In the case of Trifles, Susan Glaspell wrote the play in informal conversational English. However, it was translated into the formal style of Modern Standard Arabic rather than informal Arabic. The style shift in the translation of Trifles into Arabic was not merely a random choice made by the translator. It was rather an appropriate approach to be employed in order to achieve extensive readability and comprehensibility by readers and viewers of the Arabic version of the play. Modern Standard Arabic is the only form of Arabic that can be written and thus be understood by all Arab nations. Other varieties of Arabic are considered to be deviations from the norms of writing. According to Al-Qinai (2009), attempts to write informal spoken Arabic have in past centuries been denied by Arab linguists as they were considered to be violations of language norms that would harm the purity of Arabic. To some extent, this was because of the nationalistic intelligentsia movement in the 1900s that attempted to rejuvenate Classical Arabic as a common form of language among all Arabs.

Al-Qinai (2006) suggests that there are two major reasons for style shifting in translation: linguistic and cultural. The latter may take place if the translator is required to substitute a particular type of style with another to re-adjust the translation to the general norms of the target language and its culture. As a result, the translator may see that it is culturally desirable to translate the informal style of a source language text by a formal target language style. As stated by Catford (1965), an English youth may easily address his father in a casual style, while an oriental youth may have to use an honorific style in the same situation. Hence, Mares (2012) asserts that translation from English to Arabic is usually restricted to the formal register rather than an informal variety. Similarly, Al-Qinai (2006) affirms that when translating informal source language texts into Arabic, translators tend to opt for the formal variety as there are almost no possible written equivalents for most informal English words and phrases. Therefore, when translating informal dialogues in English novels, plays, and film scripts into Arabic, translators tend to upgrade the register by using more sophisticated vocabulary, more cohesive ties, and well-structured sentences. Here, the style shift in translation from informal to formal language would be evident in the target language text and would be regarded as normal usage of Arabic by readers and viewers (Al-Qinai, 2009).

In the translation of Trifles into Arabic, the style shifts are demonstrated in the translation of a number of linguistic phenomena, namely contraction, elision 
(aphaeresis, syncope, and apocope), subject-verb agreement, and figurative multi-word expressions (phrasal verbs, and idiomatic expressions). Therefore, this study examined these aspects of informality in the source language text and the way they were translated into Arabic.

\subsection{Contraction}

A contraction is a linguistic phenomenon that involves a phonological process (Ito, 2005). Nevertheless, not all aspects related to contraction can be explained through phonology, as syntactic constraints govern their occurrence as well (Lakoff, 1970). Contractions occur in connected speech and may possibly involve a range of processes such as vowel reduction, consonant deletion, voicing/devoicing, and nasalisation (Ito, 2005).

In English, a contraction is a combination of two or more words that are mostly attached with an apostrophe, thereby creating one shortened word. One or more letters are removed from the constituents of the contraction when they are attached. Contractions are frequently evident in spoken language and informal writing, while they are usually discouraged in formal writing settings. The reason behind using contractions by language speakers is usually to save time in speech and possibly to maintain an informal tone. On the other hand, formal language is maintained by avoiding contractions, which serves to establish a more serious tone. Common examples of contractions in English are isn't (is not), that's (that is), don't (do not), gonna (going to), wanna (want to), I'd (I would or I had) and she'll (she will).

Contractions are also evident in Arabic speech; however, they are not represented in writing. Cases of contraction include the phonological phenomenon of idghaam (a merger of two sounds) in Arabic. It refers to the meeting of a consonant letter with a vowel letter so that the two letters become a single emphasised letter. The idghaam is caused when the consonant sound $ن$ $(/ \mathrm{n} /)$ pronounced with a sukoon (when no sound is pronounced after the sound $\mathrm{u} / \mathrm{n} /$ at the end of a word) is immediately followed by one of the following

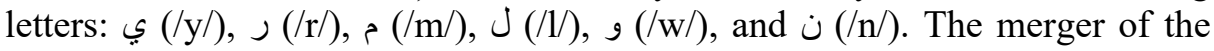
sequence of sounds (i.e. the end of one word with the beginning of the immediately following word) forms a compound word that should be treated as one entity when it is pronounced. An example provided by AbuZeina et al. (2011) is the combination of the two Arabic words 'an malaa'ib (literally 'of playgrounds') creating the pronunciation of the contraction /'ammalaa'ib/, which is only spoken but never written. Another case of contraction that occurs in Arabic is the iqlaab (a conversion of a sound). It takes place if the consonant sound $ن(/ \mathrm{n} /)$ pronounced with a sukoon is immediately followed by the letter $(/ \mathrm{b} /)$. This sequence of sounds could possibly occur within one word or in between two words. When iqlaab occurs, the $\dot{u}(/ \mathrm{n} /)$ is changed into $p(/ \mathrm{m} /)$ in pronunciation. The word 'anbar ('ambergris') is an example of this type of contraction in Arabic, where it is pronounced /'ambar/ instead. Another example of iqlaab when it takes place in between two words is $\min b a^{\prime} d$ ('afterwards'), where the actual pronunciation is /mimba'd/.

There are a total of 163 occurrences of contractions in Trifles. The vast majority of these contractions are very common in English informal writing. Common contractions include a subject pronoun or noun plus a verb, a verb plus not, and a subject pronoun plus have, etc. (e.g. I'm, isn't, shouldn't, they've).

In spite of this, there are contractions in Trifles that are much less common in informal writing, as they are not observed very often. Some of the unfamiliar or marked contractions might cause difficulty in understanding for translators if read out of context or mispronounced because of their rare usage in written form. Examples of marked contractions in Trifles are illustrated in Table 1. 
Table 1: Examples of marked contractions in Trifles

\begin{tabular}{|c|c|c|}
\hline Marked contraction & Full form & Context \\
\hline fire'd & fire would & $\begin{array}{c}\text { The fire'd go out and her jars } \\
\text { would break. }\end{array}$ \\
\hline place'd & place would & $\begin{array}{c}\text { But I don't think a place'd be any } \\
\text { cheerfuller for John Wright's being } \\
\text { in it. }\end{array}$ \\
\hline does'll & does will & $\begin{array}{c}\text { I suppose anything Mrs. Peters } \\
\text { does'll be all right. }\end{array}$ \\
\hline 'tis & it is & I s'pose 'tis. \\
\hline
\end{tabular}

The Arabic translations of the marked contractions in Trifles do not contain any contractions. That is to say that the informal English contractions were translated into full form words according to the norms of Arabic writing. It is impossible for a translator to translate the informal English contractions using contractions in Arabic for three reasons. First, contractions in Arabic are not as common as they are in English. Second, contractions in English do not have equivalent contractions in Arabic. Third, contractions in Arabic are only pronounced but are not evident in writing.

\subsection{Elision}

An elision or deletion in linguistics is the omission of one or more sounds in a word or phrase (McCarthy, 2002). Examples of elision include aphaeresis, syncope, and apocope. Elision at the beginning of a word is called aphaeresis (e.g. the word 'gator,' which is short for 'alligator'). Elision in the middle of a word is referred to as syncope (e.g. the word 'ma'am', which is short for 'madam'). Elision at the end of a word is identified as apocope or apocopation (e.g. the word 'ad', which is short for 'advertisement').

In Arabic, elision also exists, but is far less common than in English. An example of apocope in Arabic is the linguistic phenomenon named by grammarians as tarkheem (literally 'softening'), which is the shortening by the elision of the final consonant (Ziadeh, 1986). An example of tarkheem in Arabic is the shortening of the noun SaaHib ('friend') into SaaH (omitting the final consonant). Examples of elision that were used in Trifles are presented in Table 2.

The elision examples in Trifles were all translated into Arabic by full-form words. The Arabic translation did not contain any elisions for three reasons, namely because they are rare in Arabic in general, they are mostly not evident in Arabic writing, and the specific English elisions concerned do not correspond to elisions employed in written Arabic. 
Table 2: Examples of elision in Trifles

\begin{tabular}{|c|c|c|c|}
\hline Elision & Elision type & Full form & Context \\
\hline rockin' & apocope & rocking & She was rockin' back and forth. \\
\hline $0^{\prime}$ & apocope & of & "No," she says, kind o' dull like. \\
\hline 'cause & aphaeresis & because & 'Cause he's dead. \\
\hline rockin' & apocope & rocking & ... rockin' back and forth. \\
\hline pleatin' & apocope & pleating & $\begin{array}{c}\text {...and just went on pleatin' at her } \\
\text { apron. }\end{array}$ \\
\hline lyin' & apocope & lying & ...and there he was lyin'. \\
\hline pleatin' & apocope & pleating & $\begin{array}{c}\text {...and she stopped pleatin' of her } \\
\text { apron. }\end{array}$ \\
\hline sleepin' & apocope & sleeping & $\begin{array}{l}\text { "Weren't you sleepin' in the bed with } \\
\text { him?" }\end{array}$ \\
\hline ‘a & $\begin{array}{l}\text { aphaeresis } \\
\text { and apocope }\end{array}$ & have & $\begin{array}{l}\text { We must 'a looked as if we didn't see } \\
\text { how that could be }\end{array}$ \\
\hline worryin' & apocope & worrying & $\begin{array}{l}\text { Held for murder and worryin' about } \\
\text { her preserves. }\end{array}$ \\
\hline sayin' & apocope & saying & $\begin{array}{l}\text { and he'll make fun of her sayin' she } \\
\text { didn't wake up. }\end{array}$ \\
\hline s'pose & syncope & suppose & I s'pose 'tis. \\
\hline goin' & apocope & going & $\begin{array}{l}\text { I wonder if she was goin' to quilt or } \\
\text { just knot it? }\end{array}$ \\
\hline takin' & apocope & taking & $\begin{array}{l}\text {...our takin' up our time with little } \\
\text { things while we're waiting for them to } \\
\text { get the evidence. }\end{array}$ \\
\hline s'pose & syncope & suppose & I s'pose maybe the cat got it. \\
\hline
\end{tabular}

\subsection{Improper subject-verb agreement}

Subject-verb agreement is a grammatical term used to represent the relationship between two grammatical units in a sentence (Quirk et al., 1985). Agreement or concord is the association between two grammatical units wherein one of them demonstrates a particular feature that accords with a displayed or semantically implicit feature in the other. In other words, this type of grammatical agreement is achieved when the verb shows full agreement with the subject in the features of person, number and gender.

There are several occurrences of improper subject-verb agreement in Trifles, which is a linguistic issue that is considered common in some regional dialects in the US (Russell, 1997). The sentences in Table 3 are examples of such improper grammatical structures in Trifles.

Table 3: Examples of improper subject-verb agreement in Trifles

\begin{tabular}{|l|l|}
\hline \multicolumn{1}{|c|}{ Improper subject-verb agreement } & \multicolumn{1}{c|}{ Grammatical correction } \\
\hline${ }^{*}$ then I says... & then I said... \\
\hline${ }^{*}$ This is cherries, too. & $\begin{array}{l}\text { This is a cherry, too / These are cherries, } \\
\text { too. }\end{array}$ \\
\hline${ }^{*}$ This all you was to take? & This is all you were to take? \\
\hline $\begin{array}{l}\text { *She said they was in the top drawer in } \\
\text { this cupboard. }\end{array}$ & $\begin{array}{l}\text { She said they were in the top drawer in this } \\
\text { cupboard. }\end{array}$ \\
\hline $\begin{array}{l}* \ldots \text { when they was slipping that rope under } \\
\text { his neck. }\end{array}$ & $\begin{array}{l}\text {... when they were slipping that rope under } \\
\text { his neck. }\end{array}$ \\
\hline${ }^{*} .$. this isn't her scissors. & ...these aren't her scissors. \\
\hline
\end{tabular}

Improper subject-verb agreement results in errors that are described by Ferris and Hedgcock $(2014$, p.283) as "deviations from the grammatical rules of a language that violate the intuitions or expectations of literate adult native speakers of that language." Although there are cases of improper subject-verb 
agreement in Trifles, the Arabic translation does not contain any. When a translator translates into Arabic, accuracy refers to the error-free production of language forms in writing. Therefore, the cases of improper subject-verb agreement in Trifles were translated into grammatical sentences in Modern Standard Arabic, as it would be grammatically unacceptable, according to the norms of Arabic writing, to translate them in any other way.

\subsection{Figurative multi-word expressions}

Masini (2005, p.145) states that multi-word expressions are "lexical units larger than a word that can bear both idiomatic and compositional meanings." These expressions are evident in almost all languages, including English and Arabic. It can also be said that the term multi-word expression may cover a number of linguistic occurrences in a language, ranging from free collocations to fixed expressions. Hüning and Schlücker (2015, p. 451) assert that multi-word expressions include different types of figurative phrases, such as proverbs (e.g. 'a bird in the hand is worth two in the bush'); idiomatic expressions (e.g. 'to kick the bucket'); phrasal verbs (e.g. 'to make up'); and similes (e.g. 'as nice as pie').

Only informal figurative expressions will be discussed here since this study is concerned with style shift in the translation of informal English into formal Arabic. Therefore, there are a number of occurrences of informal figurative multi-word expressions in Trifles, specifically idiomatic expressions and phrasal verbs.

\subsubsection{Idiomatic expressions}

According to the Oxford Dictionary, an idiomatic expression is "a phrase whose meaning is difficult or sometimes impossible to guess by looking at the meaning of the individual words it contains" (Hornby et al., 2000, p.752). Even if one understands the meaning of the individual words in an idiomatic expression, the meaning of the whole phrase can still be difficult to comprehend. As in English, Arabic contains idiomatic expressions. However, not all idiomatic expressions in a language may necessarily have an equivalent in another. Table 4 illustrates the examples of idiomatic expressions in Trifles.

Table 4: Examples of idiomatic expressions in Trifles

\begin{tabular}{|l|l|}
\hline \multicolumn{1}{|c|}{ Idiomatic expressions } & \multicolumn{1}{c|}{ Formal expression/meaning } \\
\hline I had my hands full. & very busy \\
\hline $\begin{array}{l}\text { I don't think she minded..one way or } \\
\text { other. }\end{array}$ & whatever the outcome \\
\hline He's dead all right. & certainly or without any doubt \\
\hline Here's a nice mess. & a difficult situation with a lot of problems \\
\hline $\begin{array}{l}\text { I want to get the lay of things upstairs } \\
\text { now. }\end{array}$ & $\begin{array}{l}\text { to get the appearance of something and } \\
\text { where each part of it is }\end{array}$ \\
\hline $\begin{array}{l}\text { I suppose anything Mrs. Peters does'll be } \\
\text { all right. }\end{array}$ & suitable, satisfactory or acceptable \\
\hline $\begin{array}{l}. . \text { keep an eye out for anything that might } \\
\text { be of use to us. }\end{array}$ & $\begin{array}{l}\text { look out for or check something with } \\
\text { particular attention }\end{array}$ \\
\hline $\begin{array}{l}\text { I think maybe that's why she kept so } \\
\text { much to herself. }\end{array}$ & refuse to disclose or share something \\
\hline $\begin{array}{l}\text { He'll make fun of her sayin' she didn't } \\
\text { wake up. }\end{array}$ & $\begin{array}{l}\text { to make unkind insulting remarks about } \\
\text { someone or something }\end{array}$ \\
\hline $\begin{array}{l}\text { Now let's go up again and go over it piece } \\
\text { by piece. }\end{array}$ & one part at a time \\
\hline $\begin{array}{l}\text { We ought to take a look at these } \\
\text { windows. }\end{array}$ & to check something \\
\hline
\end{tabular}


The above examples of the idioms were translated into Arabic with formal expressions that represent their meanings. Although some of the idiomatic expressions in Trifles may have equivalents in Arabic, the translator instead chose to provide their meanings so that they may be understood across the Arab world, and to avoid any misinterpretations. That is because an Arabic idiomatic expression used in one Arab country or region may sound meaningless in another.

\subsubsection{Phrasal verbs}

Phrasal verbs in English are sometimes referred to as two-word verbs. They comprise a verb and one or two prepositions. A phrasal verb may carry two types of meanings: a literal or non-idiomatic meaning, and a figurative or idiomatic meaning. The figurative nature of phrasal verbs makes them nontransparent and sometimes difficult to comprehend from their constituent components, thereby resulting in a new semantic unit different to the verb itself. As a consequence, Thrush (2001, p.293) suggests that 'the meaning of the phrasal verb cannot be derived by looking up the verb and the preposition separately in a dictionary'. Therefore, Aldahesh (2008) affirms that phrasal verbs are sometimes problematic for most translators because of their figurative nature. Examples of phrasal verbs in Trifles are presented in Table 5.

The examples of the phrasal verbs in Trifles were all translated into Arabic by their intended meanings. It is normally impossible to translate them by equivalent phrasal verbs because they do not exist in Arabic. However, Arabic contains a linguistic phenomenon that may share some features of English phrasal verbs, namely prepositional verbs (Mubarak, 2015). A prepositional verb in Arabic is simply a verb plus preposition. Subsequently, verb transitivity in Arabic may be possible by including a preposition after the verb. Examples of Arabic verb plus preposition phrases that are to some extent similar to English phrasal verbs are as follows. The verb raghiba (literally 'to want') followed by the preposition fii (literally 'in') means to be interested in something, while the same verb followed by the preposition 'an (literally 'about') means not to be interested in something.

Needless to say, not all multi-word expressions in English have ready equivalent expressions in Arabic. When there happens to be no equivalent, translators tend to provide their intended meanings in the target language by following the normalisation procedure of translation, which may be defined as "the tendency to conform to patterns and practices which are typical of the target language" (Baker, 1996, p.176). In the case of translating Trifles into Arabic by Brashi (2019), the translator translated the multi-word expressions by their intended meanings that adhere to the norms of formal Arabic. Hence, the multiword expressions were 'normalised' in Arabic by the translator into commonplace phraseology. 
Table 5: Examples of phrasal verbs in Trifles

\begin{tabular}{|l|l|}
\hline \multicolumn{1}{|c|}{ Phrasal verbs } & \multicolumn{1}{c|}{ Meaning } \\
\hline Come up to the fire, ladies. & to move towards \\
\hline $\begin{array}{l}\text { Now, Mr. Hale, before we move things } \\
\text { about, you explain to Mr. Henderson just } \\
\text { what you saw when you came here } \\
\text { yesterday morning. }\end{array}$ & to move from place to place \\
\hline $\begin{array}{l}\text { I knew you could get back from Omaha by } \\
\text { today. }\end{array}$ & to return \\
\hline We came along the road from my place. & to come / to accompany \\
\hline ..to go in with me on a party telephone. & to join or subscribe \\
\hline ...he put me off. & to discourage \\
\hline She was ... kind of done up. & to be exhausted \\
\hline $\begin{array}{l}\text { She didn't ask me to come up to the } \\
\text { stove... }\end{array}$ & to move towards \\
\hline Soon Harry got back. & to return \\
\hline ...the fire'd go out. & to be extinguished \\
\hline You mean that they didn't get on very well? & to live together in harmony \\
\hline $\begin{array}{l}\text { Seems mean to talk about her for not } \\
\text { having things slicked up. }\end{array}$ & to tidy up \\
\hline $\begin{array}{l}\text {...when she had to come away in such a } \\
\text { hurry. }\end{array}$ & to leave \\
\hline $\begin{array}{l}\text { I remember the afternoon I put up my } \\
\text { cherries last summer. }\end{array}$ & to store and preserve food \\
\hline $\begin{array}{l}\text { Shaking off the mood which the empty } \\
\text { rocking chair has evoked. }\end{array}$ & to discard something bad \\
\hline $\begin{array}{l}\text { They say it was such a --funny way to kill a } \\
\text { man, rigging it all up like that. }\end{array}$ & to contrive \\
\hline $\begin{array}{l}\text { Locking her up in town and then coming out } \\
\text { here and trying to get her own house to turn } \\
\text { against her! }\end{array}$ & to oppose someone \\
\hline Better loosen up your things. & to untie or make looser \\
\hline $\begin{array}{l}\text { let's go out to the barn and get that cleared } \\
\text { up. }\end{array}$ & $\begin{array}{l}\text { to go out = to leave } \\
\text { to clear up = to check thoroughly }\end{array}$ \\
\hline It might take up her mind. & to use or occupy \\
\hline $\begin{array}{l}\text { Now let's go up again and go over it piece } \\
\text { by piece. }\end{array}$ & to examine \\
\hline We mustn't..t take on. & to become upset \\
\hline $\begin{array}{l}\text { Getting all stirred up over a little thing like } \\
\text { a--dead canary. }\end{array}$ & to agitate or disturb \\
\hline $\begin{array}{l}\text { I guess they're not very dangerous things } \\
\text { the ladies have picked up. }\end{array}$ & to collect, find or acquire \\
\hline
\end{tabular}

\section{Discussion and conclusion}

In English literature, authors may use informal language in some literary genres to create dialogue that seems more authentic and real. Trifles is an example of a play characterised by comprising many informal instances that are justified in English literary works. In the case of translation from English into Arabic, most translation shifts appear to be motivated by formality differences between source and target languages. These style shifts may be considered as obligatory shifts.

The stylistic shift in the Arabic translation of Trifles included various shifts of register (formality). The shifts were due to an adherence to Arabic norms of acceptable writing. Therefore, style shifting was endorsed in the translation of Trifles, as it was not practical to translate informal conversational English into an informal style in Arabic. The formal style was used in the target language 
text because the translator sought comprehension and clarity in language and opted for a better understanding of the meaning of the source text. Hence, the translator used simple vocabulary with the intention to satisfy the expectations of the target language readership in all Arab states.

The present study examined an example of diglossic style shifting in a translation from English to Arabic. It showed how Arabic tends to resist informality in writing. A conclusion that can be reached in this article is that formal Arabic may later be shifted to different informal dialectal varieties of Arabic when the translated version of the play, Trifles, is performed on stage. This is just one step towards reaching a communicative version of the translation, which enhances not only verbal but also non-verbal expressions of meaning and thought. At this point, communication refers to the connection between the actors of the play on stage and the audience. Therefore, it may be considered an important aspect of a successful theatrical experience as communication takes place in both directions. That is, the message conveyed on stage is directed towards the audience and an instantaneous response is expected on their part.

The dialectal version of informal Arabic would then depend on the region and country in which it will be performed. This, of course, entails the adaptation of the play to informal Arabic. Given the fact that languages change gradually, the dialectal version of Arabic of one period in time may not remain the same in another. Therefore, in order for the play to come alive, the formal Arabic version of Trifles by Brashi (2019) may need to be customised or adapted to one or more specific dialects of Arabic according to the time and place of the performance. This can be carried out by scenarists or scriptwriters of specific dialects in different Arab states. It would be practical if these scriptwriters had competent knowledge of colloquial English themselves. If they would just rely on the standard Arabic translation, then the sociolinguistic markers they use in their dialectal versions of the play would be mostly considered a form of adaptation.

\section{References}

Aaltonen, S. (2010). Drama translation. In Y. Gambier, \& L. van Doorslaer (Eds.), Handook of Translation Studies (Vol. 1, pp. 105-110). Amsterdam: John Benjamins Pub. Co.

AbuZeina, D., Al-Khatib, W., Elshafei, M., \& Al-Muhtaseb, H. (2011). Cross-word Arabic pronunciation variation modeling for speech recognition. International Journal of Speech Technology, 14(3), 227-236. https://doi.org/10.1007/ s10772011-9098-0

Al Merabi, D. (2011). The economy of standardization and dialect variability in Arabic (Unpublished MA thesis). University of Regina, Canada.

Albakry, M. (2014). Between the human and the foreign: Translating Arabic drama. Educational Theory, 64(5), 497-514. https://doi.org/10.1111/edth.12077

Albirini, A. (2014). The role of the colloquial varieties in the acquisition of the standard variety: The case of Arabic heritage speakers. Foreign Language Annals, 47(3), 447-463. https://doi.org/10.1111/flan.12087

Aldahesh, A. Y. (2008). Translating idiomatic English phrasal verbs into Arabic (Unpublished doctoral thesis). University of Western Sydney, Australia.

Al-Qinai, J. (2006). Code-switching and style shift in translation. In C. M. Figueroa, \& T. M. Gárate, Studies in contrastive linguistics: Proceedings of the 4th International Contrastive Linguistics Conference, Santiago de Compostela, September, 2005 (pp. 45-57). Univ Santiago de Compostela Publicacións.

Al-Qinai, J. (2009). Style shift in translation. Journal of Pan-Pacific Association of Applied Linguistics, 13(2), 23-41.

Baker, M. (1996). Corpus-based translation studies: The challenges that lie ahead. In M. Baker, \& H. Somers (Eds.), Terminology, LSP and translation: Studies in 
language engineering in honour of Juan C. Sager (pp. 175-186). Amsterdam: John Benjamins Publishing Company.

Brashi, A. (2019). An Arabic translation of Susan Glaspell's play, "Trifles". International Journal of Comparative Literature and Translation Studies (IJCLTS), 7(4), 14-28. http://dx.doi.org/10.7575/aiac.ijclts.v.7n.4p.14

Catford, J. C. (1965). A Linguistic theory of translation. Oxford: Oxford University Press.

Ferris, D. R., \& Hedgcock, J. S. (2014). Teaching L2 composition: Purpose, process and practice (3rd ed.). New York: Routledge.

Glaspell, S. (1916). Trifles. New York: Frank Shay, the Washington Square Players.

Hilton, L. (2011). Trifles, by Susan Glaspell. Women \& Performance: A Journal of Feminist Theory, 21(1), 147-149. https://doi.org/10.1080/0740770X.2011. 563045

Holes, C. (2004). Modern Arabic: Structures, functions and varieties (Revised ed.). Washington, D.C.: Georgetown University Press.

Holstein, S. C. (2003). Silent justice in a different key: Glaspell's "Trifles". Midwest Quarterly: A Journal of Contemporary Thought, 44(3), 282-290.

Hornby, A. S., Ashby, M., \& Wehmeier, S. (2000). Oxford advanced learner's dictionary of current English (6th ed.). Oxford: Oxford University Press.

Huang, L., \& Chu, C. (2014). Translator's style or translational style? A corpus-based study of style in translated Chinese novels. Asia Pacific Translation and Intercultural Studies, 1(2), 122-141. http://doi.org/10.1080/23306343.2014. 883742

Hüning, M., \& Schlücker, B. (2015). Multi-word expressions. In P. O. Müller, I. Ohnheiser, S. Olsen, \& F. Rainer (Eds.), Word-formation: An international handbook of the languages of Europe (Vol. 1, pp. 450-466). Berlin: De Gruyter Mouton.

Ibsen, H. (2006). Beit El Domia [A doll's house]. (K. Youssef, Trans.). Cairo: Maktabat al-funūn al-drāmiyya. (Original work published 1879 ).

Ito, Y. (2005). A psycholinguistic approach to Wanna contraction in second language acquisition (Unpublished doctoral thesis). University of Hawai'i, USA.

Jabboury, L. I. (2007). The significance of symbolism in conveying the feminist perspective in Susan Glaspell's Trifles. Mustansiriyah Journal of Arts, 33(47), 122.

Jayyusi, S. K. (Ed.). (2006). Beyond the dunes: An anthology of modern Saudi literature. London and New York: I.B. Tauris.

Kennedy, J. (2014). A History of the Provincetown Playhouse. Retrieved December 1, 2018, from The Provincetown Playhouse: http://wwwprovincetownplayhouse. com/history.html

Lakoff, G. (1970). Global rules. Language, 46(3), 627-639.

Leech, G., \& Short, M. (2007). Style in fiction: A linguistic introduction to English fictional prose (2nd ed.). London: Pearson Education Limited.

Mares, R. (2012). Cultural difficulties in translations from English into Arabic. Analele Universitatii Crestine Dimitrie Cantemir, Seria Stiintele Limbii,Literaturii si Didactica predarii, 1(1), 69-77.

Masini, F. (2005). Multi-word expressions between syntax and the lexicon: the case of Italian verb-particle constructions. SKY Journal of Linguistics, 18, 145-173.

McCarthy, J. (2002). A thematic guide to optimality theory. Cambridge: Cambridge University Press.

Mubarak, L. A. (2015). Phrasal verbs in English and Arabic: A contrastive study with reference to some scientific texts. Journal Of Babylon Center for Humanities Studies, 5(1), 1-22.

Quirk, R., Greenbaum, S., Leech, G., \& Svartvik, J. (1985). A comprehensive grammar of the English language. London: Longman.

Russell, J. K. (1997). Glaspell's Trifles. The Explicator, 55(2), 88-90. https://doi.org/10.1080/00144940.1997.11484130

Sutton, B. (2008). "A different kind of the same thing": Marie de France's Laüstic and Glaspell's Trifles. The Explicator, 66(3), 170-174. https://doi.org/10.3200/ EXPL.66.3.170-174

Thrush, E. A. (2001). Plain English? A study of plain English vocabulary and international audiences. Technical Communication, 48(3), 289-296.

Ziadeh, F. J. (1986). Prosody and the initial formation of Classical Arabic. Journal of the American Oriental Society, 106(2), 333-338. https://doi.org/10.2307/601598 